\title{
The Serological Differentiation of Acute and Chronic Schistosomiasis Japonica Using IgA Antibody to Egg Antigen
}

\author{
Cen Liping/+ , LG Viana*, TC Melo Garcia*, ALT Rabello*, N Katz*
}

Hubei Institute of Schistosomiasis Control, Wuhan, 430070 Hubei, People's Republic of China *Centro de

Pesquisas René Rachou-FIOCRUZ, Av. Augusto de Lima 1715, 30190-002 Belo Horizonte, MG, Brasil

Two groups of Schistosoma japonicum infected patients (acute and chronic) and non-infected individuals were studied using IgA antibody to egg antigen (SEA) and IgG and IgM antibodies to keyhole limpet haemocyanin $(K L H)$. The means and standard deviation of the optical density in ELISA

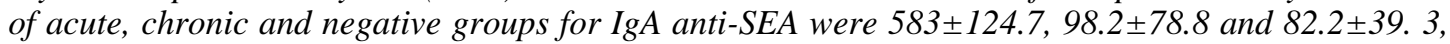
respectively. There was a statistically significance between acute patients and chronic patients $(P<0.01)$. The means and standard deviation of IgG and IgM antibodies to KLH were 501.5 $\pm 150.6,113.0 \pm 79.1$, $28.8 \pm 56.3$ and $413.6 \pm 148.5,70.2 \pm 14.8,65.3 \pm 45.3$, respectively. The detection results of IgA to SEA compared with the IgG and IgM to KLH did not demonstrate a significant difference $(P>0.01)$. The sensitivities of IgA to SEA and IgG and IgM antibodies to KLH for the detection of acute infection were $95.24 \%, 90.48 \%$ and $85.71 \%$, respectively. Therefore, this study showed that the detection of IgA to SEA is also a useful new method for the serological differentiation of acute and chronic schistosomiasis japonica in humans.

Key words: acute and chronic schistosomiasis japonica-serological differentiation

Although the present frequency of acute infection in China is much less than it was in the 1950s and 1960s, thousands of acute infections are still reported in the marshlands and lake regions (Zhang 1985,1987, Mao 1986, Anonymous 1989). From 1980 to 1988 the total number of acute cases due to Schistosoma japonicum infection has been fluctuating between 2, 400 and 7,000 per year in China (Wang \& Jia 1989).

The clinical findings of acute schistosomiasis mansoni may easily be confused with a number of infectious diseases such as malaria, typhoid fever, visceral leishmaniasis, miliary tuberculosis, viral hepatitis, mononucleosis, salmonella infection or influenza and bacterial infections (Beaver et al. 1984, Chapman et al. 1988). The infected patients present a serious syndrome including: fever, weakness, loss of weight, diarrhoea, abdominal pain, cough, myalgia, arthralgia, urticaria, edema and enlargement of the liver and spleen (Neves 1965, Lambertucci 1993), which are markedly similar to acute schistosomiasis japonica. Acute $S$. japonicum infection causes severe morbidity in China, whereas acute $S$. haematobium and S. mansoni infection, which are usually self-limiting, may be fatal if untreated (Nash et al. 1982, Chen \& Mott

${ }^{+}$Corresponding author. Tel: +86-27-786.0567

Received 19 March 1996

Accepted 4 July 1996
1988). Misdiagnosis appears to be common during this phase of the disease (Houpis et al. 1984, Chapman et al. 1988). Therefore, it is necessary to look for a fast and early method of schistosomiasis diagnosis in humans.

Experimental studies have demonstrated the existence of a shared carbohydrate epitope between keyhole limpet haemocyanin (KLH) and schistosomulum surface antigens of S. mansoni (Grzych et al. 1987, Mansour et al. 1989). The high levels of antibodies against KLH were observed only in acutely infected patients (Omer et al. 1989). Thus, KLH serves as a means of rapid and easy identification of individuals with acute schistosomiasis infections of $S$. haematobium (Mansour et al. 1989), S. mansoni (Alves et al. 1992, Rabello et al. 1993) and S. japonicum (Yushen et al. 1994).

Recently, high-level IgA antibody to egg antigen (SEA) was observed in acutely infected patients of $S$. mansoni. The rate of detection was $100 \%$ (Rabello et al. 1995). In this paper we report high-level anti-SEA IgA antibody in individuals with acute $S$. japonicum infection in China.

\section{MATERIALS AND METHODS}

Patients - Acute sera - 21 cases were obtained from the highly endemic area in Wuchang county, Hubei provence, People's Republic of China, one month after contact with water contaminated with cercariae of $S$. japonicum and presenting with fever, diarrhoea and liver enlargement clinical mani- 
festation. The patients were 9-43 years old, geometric mean number of $S$. japonica eggs was 63.5 per gram. Their faeces were examined by the KatoKatz technique (Katz et al. 1972). Chronic sera: 21 cases were obtained from the highly endemic area in Jianling country, also identified by stoolexamination. The geometric mean number of $S$. japonicum eggs was 54.8 per gram. Normal sera: 20 cases were obtained from healthy individuals that served as normal controls with negative stool examination.

Enzyme-linked immunosorbent assay - A standard micro-well enzyme-linked immunosor-bent assay (ELISA) using Nunc-Immuno plates (Maxisorp), IgA, IgM and IgG-Peroxidase conjugates (Sigma), and a Bio-Rad ELISA reader was employed. The methods of ELISA have been described in Rabello et al. (1993, 1995).

Optical densities greater than the mean value plus two standard deviations of the sera from chronically infected individuals were considered to indicate acute schistosomiasis (Mansour et al. 1989).

Statistical analysis - Students' T test was used to determine the significant differences in antibody response, using the ELISA optical density values, between the acute and chronic groups of patients. The EPIINFO V.6 program was used for statistical analysis.

\section{RESULTS}

The means and standard deviation of the optical density in ELISA of acute, chronic and negative groups for anti-SEA IgA were 583.2 \pm 124.7 , $98.2 \pm 78.8$ and $82.2 \pm 39.3$, respectively; for antiKLH IgM and $\operatorname{IgG}$ were 413.6 $\pm 148.5,70.2 \pm 14.8$ and $65.3 \pm 45.3$ and $501.5 \pm 150.6,113.0 \pm 79.1$ and $28.8 \pm 56.3$, respectively. There was a statistically significant difference between acute and chronic patients for anti-SEA IgA antibody $(\mathrm{P}<0.01)$ (Fig. 1), as well as for IgM and IgG to KLH (Fig. 2). The means of IgG and IgM to SEA between acute and chronic patients were not significantly different $(\mathrm{P}>0.05)$ (Fig. 3). The sensitivities of IgA antibody to SEA and IgG and IgM antibodies to KLH for the detection of acute infection were $95.24 \%$, $90.48 \%$ and $85.71 \%$, respectively, the specific ratios of IgA to SEA, IgG and IgM to KLH were $95 \%$.

\section{DISCUSSION}

This study showed that IgA antibody-level to SEA was statistically higher in the acutely infected than the chronically S. japonicum infected group. The results obtained were identical with the findings of Rabello et al. (1995). The reaction was rapid and only one false positive was found in normal

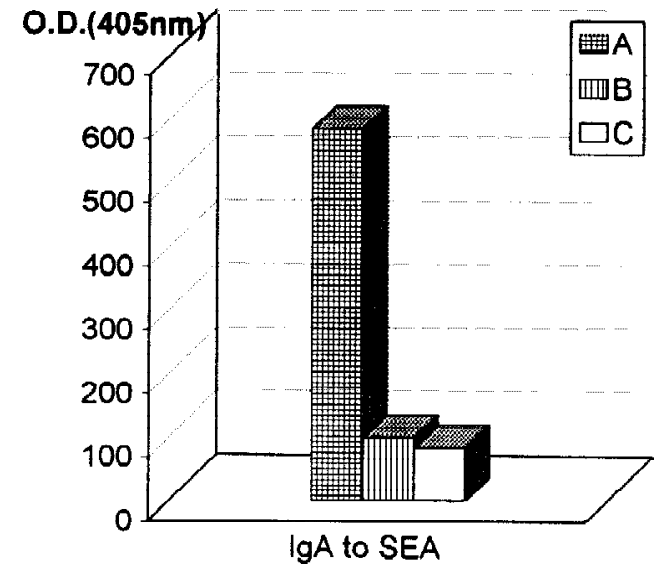

Fig. 1: means of absorbance at $405 \mathrm{~nm}$ (O.D.) in ELISA for IgA to SEA using sera from patients with (A) $n=21$ acute, (B) $n=21$ chronic schistosomiasis japonicum and (C) $n=21$ normal controls.

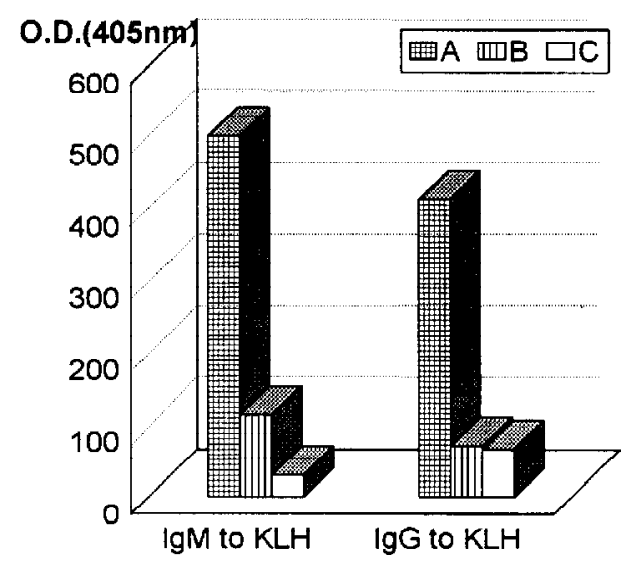

Fig. 2: means of $\operatorname{IgM}$ and $\operatorname{IgG}$ to $\mathrm{KLH}$ in (A) $\mathrm{n}=21$ acute, (B) $\mathrm{n}=21$ chronic schistosomiasis japonicum patients and $(C) \mathrm{n}=$ 20 normal controls.

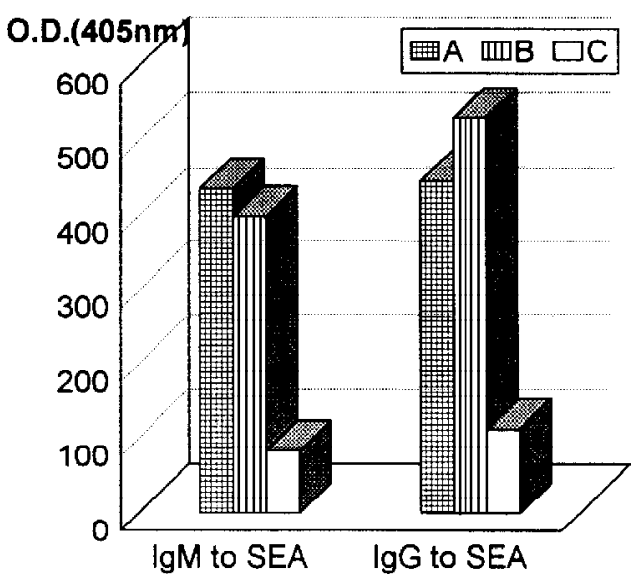

Fig. 3: the means of $\operatorname{IgM}$ and $\operatorname{IgG}$ to SEA in (A) acute, (B) chronic schistosomiasis japonicum patients and (C) normal control. 
control group. Schistosomiasis is a focally distributed disease (Kloetzel 1989). The acute form of the disease is seldom recognized in infected patients from endemic areas (Katz \& Bittencourt 1965), therefore a reliable and simple diagnostic method for the detection of acute schistosomiasis is required for patient-care in endemic and nonendemic countries, because some inhabitants of endemic countries do not live in an endemic area and people of non-endemic countries travel to endemic areas.

Previous data showed higher $\operatorname{IgA}$ responses to gut-associated antigens found in acute schistosomiasis compared to chronic schistosomiasis in studies using sections of liver granulomas (Kanamura et al. 1979), and paraffin sections of adult worms using indirect immunofluorescence (Kanamura et al. 1991).

Recently it has been demonstrated that $\operatorname{IgA}$ antibody to a 28- KD glutathione-s-transferase of $S$. mansoni seemed to play a protective role in patients with schistosomiasis, limiting egg laying and hatching (Grzych et al. 1993) and reducing the pathology related to the formation of egg granulomas (Boulanger et al. 1991).

Studies of the humoral response in acute and chronic schistosomiasis have shown that, as with cellular immune response, the antibody response to egg antigen is stronger in acutely infected patients, whereas the response to adult-worm antigens is stronger in patients with chronic infection (Gazzinelli et al. 1985, Simpson et al. 1990).

The results of this study suggest that the detection of high levels of IgA to SEA is a useful new tool for the serological differentiation of acute and chronic schistosomiasis japonica in humans. It is sufficiently sensitive, stable and rapid to make it suitable for use in the field.

\section{ACKNOWLEDGMENTS}

The study was conducted when Cen Liping was engaged in advanced studies for schistosomiasis control in Centro de Pesquisas René Rachou-FIOCRUZ, Brazil.

\section{REFERENCES}

Anonymous 1989. Schistosomiasis Advisory Committee, Ministry of Public Health Analysis on epidemiological situation of schistosomiasis in 1988 in China. Chin Schist Cont 1: 6-8.

Alves-Brito CF, Simpson AG, Bahia-Oliveira LM 1992. Analysis of anti-keyhole limpet haemocyanin antibody in brazilians supports its use for the diagnosis of acute schistosomiasis mansoni. Tran R Soc Trop Med Hyg 86: 53-56.

Beaver PC, Juny RC, Cupp EW 1984. Clinical Parasitology, 9th ed. Lea \& Febiger Philadelphia p. 432 et seq.

Boulanger D, Reid G-DF, Sturrock RF 1991. Immuni- zation of mice and baboons with the recombinant Sm 28 GST affects both viability and fecundity after experimental infection with Schistosoma mansoni. Parasite Immunol 13: 473-490.

Chapman PJC, Wilkinson PR, Daridson RN 1988. Acute schistosomiasis (Katayama fever) among British air crew. British Med J 297: 1101-1103.

Chen MG, Mott KE 1988. Progress in assesment of morbidity due to Schistosoma japonicum infection. Trop Dis Bull 85: R1-R45.

Gazzinelli G, Lambertucci JR, Katz N, Rocha RS, Lima MS, Colley DG 1985. Immune reponses during human schistosomiasis mansoni. XI. Immunologic status of patients with acute infection and after treatment. J Immunol 135: 2121-2127.

Grzych JM, Dissous C, Capron M, Torres S, Lamber PH, Capron A 1987. Schistosoma mansoni shares protective carbohydrate epitope with keyhole limpet haemocyanin. J Exp Med 165: 865-878.

Grzych JM, Grezel D, Bo Xu C 1993. IgA antibodies to a protective antigen in human schistosomiasis mansoni. J Immunol 150: 527-535.

Houpis J, Oexman J, Martin J, Jacobi G, Reardon J, Waterman G 1984. Acute schistosomiasis with transverse myclitis in American students returning from Kenya. Morbidity and Mortality. Weekly Report 33: 445-447.

Kanamura HY, Hoshino-Shimizu S, Camargo ME, da Silva LC 1979. Class specific antibodies and fluorescent staining pafferns in acute and chronic schistosomiasis mansoni. Am J Trop Med Hyg 28: 242248 .

Kanamura HY, Silva RM, Rabello ALT, Rocha RS, Katz N 1991. Anticorpo sérico IgA no diagnóstico da fase aguda da esquistossomose mansoni. Rev Inst Adolfo Lutz, 52: 101-104.

Katz N, Bittencourt D 1965. Sobre um provável caso de forma toxêmica no decurso da forma hepatoesplênica da esquistossomose mansonica. O Hospital 67: 847-858.

Katz N, Chaves A, Pellegrino J 1972. A simple device for quantitative stool thick-smear technique in schistosomiasis mansoni. Rev Inst Med Trop São Paulo 14: 397-400.

Kloetzel K 1989. Schistosomiasis in Brazil: does social development suffice? Parasitol Today 5: 388-391.

Lambertucci JR 1993. Acute schistosomiasis: clincal diagnostic and therapeutic features. Rev Inst Med Trop São Paulo 35: 399-404.

Mao SB 1986. Recent progress in the control of schistosomiasis in China. Chin Med J 99: 439-445.

Mansour MM, Omer Ali P, Farid Z, Simpson AJG, Woody JW 1989. Serological differentiation of acute and chronic schistosomiasis mansoni by antibody responses to keyhole limpet hemocyanin. Am J Trop Med Hyg 41: 338-344.

Nash TE, Cheever AW, Otlesen EA, Cook JA 1982. Schistosoma infection in humans: perspectives and recent finding. Ann Inter Med 97: 740-754.

Neves J 1965. Estudo clínico da fase pré-postural da esquistossomose mansoni. Rev Assoc Med Minas Gerais 16: 1-16. 
Omer Ali P, Mansour M, Woody LN, Smithers SR, Simpson AJG 1989. Antibody to carbohydrate and polypeptide epitopes on the surface of schistosomula of Schistosoma mansoni in Egyptian patients with acute and chronic schistosomiasis. Parasitology 98: 417-424.

Rabello ALT, Garcia MMA, Dias Neto E, Rocha RS, Katz N 1993. Dot-dye-immuno assay and dorELISA for the serological differentiation of acute and chronic schistosomiasis using keyhole limpet haemocyanin as antigen. Trans $\mathrm{R}$ Soc Trop Med Hyg 87: $279-281$.

Rabello ALT, Garcia MMA, Pinto da Silva R, Rocha RS, Chaves P, Katz N 1995. Humoral immune responses in acute schistosomiasis mansoni: Relation to morbidity. Clin Infec Dis 21: 608-615.

Simpson AJG, Xinyuan Y, Lillywhite 1990. Dissociation of antibody responses during human schistoso- miasis and evidence for enhancement of granuloma size by anti-carbohydrate IgM. Trans $R$ Soc Trop Med Hyg 84: 808-814.

Wang HZ, Jia YD 1989. Discussion on present epidemiological characteristics and control strategy of schistosomiasis in China. Clin J Schist Cont 1: 6-8.

Yuesheng L, Rabello ALT, Simpson AJG, Katz N 1994. The serological differentiation of acute and chronic Schistosoma japonicum infection by ELISA using keyhole limpet haemocyanin as antigen. Trans $R$ Soc Trop Med Hyg 88: 49-251.

Zhang JZ 1985. Epidemiological situation and control of schistosomiasis in mountainous region in China. J Parasitol Parasitic Dis 3: 301-305.

Zhang JZ 1987. Prevention and control of parasitic diseases, p. 33-35. Schistosomiasis in YL Cui, Public health in the Peoples Republic of China. Beijing, Peoples Medical Publishing House. 